\title{
Management of patients with combined pulmonary fibrosis and emphysema
}

\author{
Christina Triantafillidou ${ }^{1}$ \\ Effrosyni D. Manali2 \\ Likurgos Kolilekas ${ }^{3}$ \\ Konstantinos Kagouridis ${ }^{2}$ \\ Spyros A. Papiris²
}

$16^{\text {th }}$ Pulmonary Department, Athens Chest Hospital, Greece

$22^{\text {nd }}$ Pulmonary Medicine Department, "Attikon" University Hospital, Athens Medical School, National and Kapodistrian University of Athens, Greece

$37^{\text {th }}$ Pulmonary Department and Asthma Center, Athens Chest Hospital, Greece

Address for correspondence:

Spyros A. Papiris, MD, PhD

Head $2^{\text {nd }}$ Pulmonary Medicine Department

"Attikon" University Hospital

1 Rimini Street, 12462, Haidari, Greece

Phone: ++302105832361 - Fax: ++302105326414

E-mail: papiris@otenet.gr

\section{Summary}

Combined pulmonary fibrosis and emphysema (CPFE) was first introduced as a distinct clinical entity to describe the coexistence of any type and grade of radiological pulmonary emphysema and the idiopathic usual interstitial pneumonia CT pattern as well as any pathologically confirmed case and has been extended to include patients with emphysema and other interstitial lung diseases (ILDs), such as nonspecific interstitial pneumonia, and connective tissue disease-ILD as well. Since no certain recommendation or guideline regarding treatment strategy for CPFE patients exists, the current therapeutic option is to follow both pulmonary fibrosis and emphysema current management approach. Smoking cessation, influenza and pneumococcal vaccination should be proposed to all patients. Bronchodilator therapy could be considered in symptomatic CPFE patients with a significant obstructive pattern component in their pulmonary function testing. Dyspneic patients with CPFE might benefit from rehabilitation programs while hypoxemic patients from supplemental oxygen. No exact data exist on treatment with specific drugs for pulmonary fibrosis or/and pulmonary hypertension. In case of acute deteriora- tion best supportive care, extensive search for the etiologic factor and extended spectrum antimicrobials should be provided. Referral for lung transplantation should be encouraged in appropriate CPFE patients.

KEY WORDS: combined pulmonary fibrosis emphysema, pulmonary hypertension, acute exacerbation, lung transplantation.

\section{Characteristics of CPFE}

The concept of combined pulmonary fibrosis and emphysema (CPFE) was first introduced as a distinct clinical entity in 2005 to describe the coexistence of any type and grade of radiological pulmonary emphysema and the idiopathic usual interstitial pneumonia CT pattern as well as any pathologically confirmed case (1). However CPFE has been described in patients with other interstitial lung diseases (ILDs), such as fibrotic nonspecific interstitial pneumonia (NSIP), and connective tissue diseasefibrotic-ILD (CTD-fILD) as well (2). Since 2005 and with the increasingly utilization of CT of the chest in everyday clinical practice
CPFE presents severely reduced DLCO, volumes, severe oxygen desaturation during exercise, and high prevalence of pulmonary hypertension. preserved static lung

(Figure 1), a lot of information has appeared in the literature concerning CPFE including a number of reviews $(3,4)$, but with scarce data regarding the appropriate management of this special group of patients. Based on the existing evidence, patients with CPFE are usually older males and current or ex-smokers (1) characterized by progressive dyspnea, upper-lobe emphysema, lower-lobe fibrosis, and strong impairment of gas exchange. Diagnosis is mostly based on radiological appearance typically showing centrilobular or paraseptal emphysema in the upper lobes with reticular intralobular opacities, traction bronchiectasis and honeycombing in the lower lobes, with preserved lung volumes on plain chest radiograph as a result of two opposite conditions. Physiologically CPFE patients present severely reduced lung diffusion capacity (DLCO), preserved static lung volumes, severe impairment of gas exchange further deteriorating at exercise, and high prevalence of pulmonary hypertension $(\mathrm{PH})$ that adversely influences prognosis $(5,6)$. Actually these are the characteristic and identifiable features of this group of patients demarcating them 


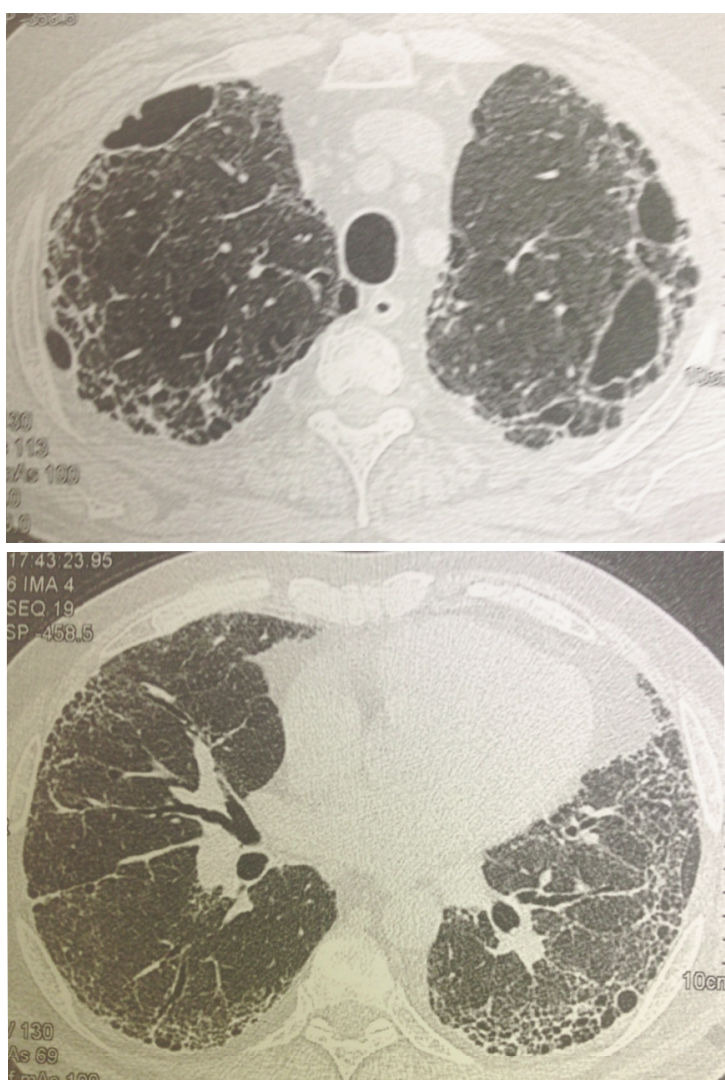

Figure 1 - Combined pulmonary fibrosis and pulmonary emphysema: characteristically emphysema is upper-lobe and fibrosis is lower-lobe predominant.

from the rest of the population of ILDs that has led to the establishment of CPFE as a distinct clinical entity. Since no certain recommendation or guideline regarding treatment strategy for CPFE patients exists, the current therapeutic option is to follow both pulmonary fibrosis and emphysema current management approach.

In most studies concerning CPFE patients the mean value of $\mathrm{FEV}_{1} / \mathrm{FVC}$ fluctuates between $67 \%$ to $78 \%$, with the majority of them including patients with $\mathrm{FEV}_{1} / \mathrm{FVC} \%$ above the threshold of $70 \%$ which characterizes airflow limitation in chronic obstructive pulmonary disease (COPD) (6-8). In addition, symptoms and signs indicative of a diagnosis of COPD such as progressive dyspnea, and chronic, more or less productive, cough could be also attributed to pulmonary fibrosis. Nevertheless, the component of emphysema which represents parenchymal destruction and its contribution to respiratory symptoms of CPFE patients should not be overlooked.

\section{Are treatments for COPD and IPF useful in pa- tients with CPFE?}

Smoking cessation, influenza and pneumococcal vaccination should be proposed to all patients (9). Regarding therapy for patients in stable state, bron- chodilator therapy with long-acting anticholinergics or beta $_{2}$-agonists is the cornerstone of COPD treatment and could be considered in symptomatic CPFE patients with a significant obstructive pattern component in their pulmonary function testing examination. The efficacy of inhaled corticosteroids is controversial in COPD patients. It has been shown that regular treatment with inhaled corticosteroids does not modify mortality in patients with COPD (9), while they are considered to increase the risk of pneumonia $(10,11)$. This is a great issue for the vulnerable population of
Clinical trials on pirfenidone and nintedanib formally excluded patients with CPFE, so no evidence-based data support the use of these drugs for CPFE. interstitial lung disease patients and therefore, inhaled corticosteroids should not be prescribed systematically in CPFE patients. Patients with CPFE can present with the clinical picture of an exacerbations of COPD, which require prompt recognition and appropriate treatment (9).

While pulmonary rehabilitation has been found to improve exercise tolerance and muscle strength, reduce the intensity of perceived dyspnea, improve quality of life and reduce the number of exacerbations for COPD patients (9), the recommendation for pulmonary rehabilitation in IPF is weak and the long-term benefit of pulmonary rehabilitation remains unclear (12-14). Dyspneic patients with CPFE might also benefit from rehabilitation programs. Patients with significant resting hypoxemia, most commonly defined as a resting $\mathrm{SpO}_{2}$ lower than $88 \%$, are entitled to supplemental oxygen (15).

Another significant parameter of the management of CPFE patients is consideration for lung transplantation. IPF accounts for the largest proportion of patients awaiting lung transplants and is associated with higher waiting-list and post-transplant mortality compared with other diseases (16). In a multicenter prospective cohort study a strong clinical association between higher mean pulmonary artery pressure (mPAP) and the risk of primary graft dysfunction among subjects with IPF following lung transplantation was found (17). This is of great importance in the CPFE population as $\mathrm{PH}$ is very common among patients of this group. Referral for lung transplantation should be encouraged in appropriate CPFE patients as it is recommended for lone-IPF patients (15).

Regarding specific treatments, IPF patients are no more treated with corticosteroids and/or other immunosuppressants (15). Moreover, there is no evidence to support the use of $n$-acetylcysteine and other immunomodulatory agents for IPF (15). The therapeutic strategy with the triple combination of steroids, azathioprine and $\mathrm{n}$-acetylcysteine has been proved harmful for the treatment of IPF patients as shown by the interim analysis of the Panther trial that demonstrated significant increase of the risk of death, hospitalizations and exacerbations at the treated group compared to the placebo arm of the study (18). Pirfenidone, a drug with anti-fibrotic and anti-inflammato- 
ry properties and a manageable tolerability profile that has been shown to slow down the progression of the disease, has been already licensed in multiple countries worldwide for the treatment of IPF, recently including Europe and the USA (19-21). In the CAPACITY trials, evidence of significant obstructive lung disease was included among exclusion criteria, despite the fact that CPFE patients were not excluded in cases of a definite diagnosis of IPF (20). In addition, in the ASCEND study, patients were excluded if they had a greater extent of emphysema than of fibrosis at the $\mathrm{HRCT}$ and if they had an $\mathrm{FEV}_{1} / \mathrm{FVC} \%$ ratio lower than $80 \%$ (21) and therefore it becomes obvious that a great proportion of CPFE patients have been excluded from the major trials that led to the introduction of pirfenidone as treatment of choice for IPF patients. Another agent approved simultaneously with pirfenidone by the FDA for the treatment of IPF is nintedanib, a triple tyrosine kinase inhibitor, which reduced the decline in FVC and possibly the time to the first acute exacerbations shown in two phase III trials (IMPULSIS-1, IMPULSIS-2) (22). In IMPULSIS studies patients with relevant airways obstruction and $\mathrm{FEV}_{1} / \mathrm{FVC} \%$ ratio less than $70 \%$ were excluded. Once again, it is not an unequivocal decision to treat CPFE patients with nintedanib, as trials have almost excluded this group of patients.

\section{CPFE and co-morbidities}

$\mathrm{PH}$ is a characteristic and common feature in the natural history of CPFE syndrome that lends clinical relevance
The risk of the development of pulmonary hypertension is notably higher in patients with CPFE than in those with idiopathic pulmonary fibrosis without emphysema. it forms a main determinant of death for them (6). All CPFE patients should undergo echocardiography for $\mathrm{PH}$ evaluation. Echocardiographic estimation for $\mathrm{PH}$ in chronic lung disease has a low positive predictive value $(32 \%)$ but a high negative predictive value (93\%) (23). Therefore, it is recommended that a diagnosis of $\mathrm{PH}$ initially diagnosed by echocardiographyis confirmed by right heart catheterization (RHC). Despite the fact that occasional cases of hemodynamic or clinical improvement have been reported with specific $\mathrm{PH}$ therapies in CPFE, there are not randomized controlled trials to support the administration of any specific treatment (24). Furthermore, no data exist to support any specific $\mathrm{PH}$ treatment in IPF patients especially after the reporting of the disappointing results of recent studies (25). Further clinical trials concerning $\mathrm{PH}$ treatments for CPFE are needed. Another great issue for CPFE patients is the risk of developing final acute deterioration events of unknown cause, the so-called acute exacerbations of IPF (AE-IPF), in this case the development of diffuse alveolar damage upon combined usual interstitial pneumonia and emphysema, with mortality approach- ing $100 \%$. AE-IPF have been described in CPFE patients, although with lower rates than in lone-IPF patients in some studies (4, 26). The evidence to support treatment of $A E$ with cor-
CPFE patients have higher risk for those with pure COPD. lung cancer than

ticosteroids is rather weak, so best supportive care, searching for the etiologic determinant and in the meantime administration of extended spectrum antimicrobials according to the immunological status of the patient since lung infection is the most common and the most treatable triggering factor, should be the only therapeutic option $(15,27)$. Interestingly, corticosteroid preoperative use has been recognized as an independent risk factor for the development of an acute exacerbation of interstitial lung disease among patients with lung cancer undergoing pulmonary resection (28).

Pulmonary fibrosis is frequently associated with lung cancer, which has a significant adverse impact on survival $(29,30)$. Among patients with pulmonary fibrosis and lung cancer, CPFE patients are more frequently encountered compared to lone-IPF patients (30). A comparison study that evaluated the risk of lung cancer among CPFE patients compared to IPF and emphysema patients concluded that CPFE and IPF patients had a higher risk of developing lung cancer than those with emphysema, although lung cancer risk was similar between CPFE and IPF (31). CPFE patients with lung cancer show a higher risk of mortality than emphysema only patients mainly due to respiratory causes, including pneumonia (8). Moreover, the occurrence of $A E$ for CPFE and lung cancer patients with the initiation of anti-cancer treatments was more often observed than for patients with isolated idiopathic interstitial pneumonias without emphysema (32). Indeed, pulmonary resection for patients with lung cancer and interstitial lung disease has been strongly associated with acute exacerbation at a substantially high rate leading to high associated mortality (28). Therefore, anticancer treatment and surgery for lung cancer should be performed with great caution in CPFE patients. Patients with CPFE who are in relatively good health and meet the recommended criteria should be offered the appropriate screening tests for lung cancer with annually low-dose HRCT of the chest (33).

Furthermore, IPF co-morbidities such as gastroeosophageal reflux, obstructive sleep apnea syndrome, depression and cardiovascular disease should be promptly diagnosed and adequately treated (34).

\section{Conclusions}

Despite the fact that CPFE is now widely considered as a distinct clinical entity with a significant early mortality, studies on specific therapeutic option for CPFE patients are completely lacking. The several IPF treatment trials should encompass a sufficient number of CPFE patients, in order to expand the use of new therapeutic agents to this population with safety. However, 
strategies against smoking would probably have the biggest impact on the natural history of this disease.

\section{Disclosure}

No financial support, no conflict of interest to declare for all authors.

\section{References}

1. Cottin V, Nunes H, Brillet PY, Delaval P, Devouassoux G, Tillie-Leblond I, et al. Combined pulmonary fibrosis and emphysema: a distinct underrecognised entity. Eur Respir J. 2005;26:586-593.

2. Cottin V, Cordier JF. Combined pulmonary fibrosis and emphysema in connective tissue disease. Curr Opin Pulm Med. 2012;18:418-427.

3. Papiris SA, Triantafillidou C, Manali ED, Kolilekas L, Baou K, Kagouridis K, et al. Combined pulmonary fibrosis and emphysema. Expert Rev Respir Med. 2013;7:19-32.

4. Jankowich MD, Rounds SI. Combined pulmonary fibrosis and emphysema: a review. Chest. 2012;141: 222-231.

5. Brillet PY, Cottin V, Letoumelin P, Landino F, Brauner MW, Valeyre D, et al. Combined apical emphysema and basal fibrosis syndrome (emphysema/fibrosis syndrome): CT imaging features and pulmonary function tests. J Radiol. 2009;90:43-51.

6. Cottin V, Le Pavec J, Prévot G, Mal H, Humbert M, Simonneau G, et al.; GERM"O"P. Pulmonary hypertension in patients with combined pulmonary fibrosis and emphysema syndrome. Eur Respir J. 2010;35: 105-111.

7. Kim YJ, Shin SH, Park JW, Kyung SY, Kang SM, Lee $\mathrm{SP}$, et al. Annual Change in Pulmonary Function and Clinical Characteristics of Combined Pulmonary Fibrosis and Emphysema and Idiopathic Pulmonary Fibrosis: Over a 3-Year Follow-up. Tuberc Respir Dis. 2014;77:18-23.

8. Lee CH, Kim HJ, Park CM, Lim KY, Lee JY, Kim DJ, et al. The impact of combined pulmonary fibrosis and emphysema on mortality. Int J Tuberc Lung Dis. 2011;15:1111-1116.

9. Global Initiative for Chronic Obstructive Lung Disease. Global strategy for the diagnosis, management and prevention of chronic obstruc $\neg$ tive pulmonary disease. Revised 2014. Available from: http://www.goldcopd.org/guidelines-global-strategyfor-diagnosis-management.html. Accessed September 14, 2014.

10. Matera MG, Cardaci V, Cazzola M, Rogliani P. Safety of inhaled corticosteroids for treating chronic obstructive pulmonary disease. Expert Opin Drug Saf. 2015;5:1-9.

11. Suissa S, Patenaude V, Lapi F, Ernst P. Inhaled corticosteroids in COPD and the risk of serious pneumonia. Thorax. 2013;68:1029-1036.

12. Holland AE, Hill CJ, Conron M, Munro P, McDonald
CF. Short term improvement in exercise capacity and symptoms following exercise training in interstitial lung disease. Thorax. 2008;63:549-554.

13. Nishiyama $\mathrm{O}$, Kondoh $\mathrm{Y}$, Kimura T, Kato K, Kataoka $\mathrm{K}$, Ogawa T, et al. Effects of pulmonary rehabilitation in patients with idiopathic pulmonary fibrosis. Respirology. 2008;13:394-399.

14. Ferreira A, Garvey C, Connors GL, Hilling L, Rigler $\mathrm{J}$, Farrell S, et al. Pulmonary rehabilitation in interstitial lung disease: benefits and predictors of response. Chest. 2009;135:442-447.

15. Raghu G, Collard HR, Egan JJ, Martinez FJ, Behr J, Brown KK, et al. ATS/ERS/JRS/ALAT Committee on Idiopathic Pulmonary Fibrosis. An official ATS/ERS/ JRS/ALAT statement: idiopathic pulmonary fibrosis: evidence-based guidelines for diagnosis and management. Am J Respir Crit Care Med. 2011;183:788824.

16. Kistler KD, Nalysnyk L, Rotella P, Esser D. Lung transplantation in idiopathic pulmonary fibrosis: a systematic review of the literature. BMC Pulm Med. 2014;14:139.

17. Fang A, Studer S, Kawut SM, Ahya VN, Lee J, Wille $\mathrm{K}$, et al. Elevated pulmonary artery pressure is a risk factor for primary graft dysfunction following lung transplantation for idiopathic pulmonary fibrosis. Chest. 2011;139:782-787.

18. Raghu G, Anstrom KJ, King TE Jr, Lasky JA, Martinez FJ. Idiopathic Pulmonary Fibrosis Clinical Research Network. Prednisone, azathioprine, and Nacetylcysteine for pulmonary fibrosis. N Engl J Med. 2012;366:1968-1977.

19. Ahluwalia N, Shea BS, Tager AM. New therapeutic targets in idiopathic pulmonary fibrosis. Aiming to rein in runaway wound-healing responses. Am J Respir Crit Care Med. 2014;190:867-878.

20. Noble PW, Albera C, Bradford WZ, Costabel U, Glassberg MK, Kardatzke D, et al. Pirfenidone in patients with idiopathic pulmonary fibrosis (CAPACITY): two randomized trials. Lancet. 2011;377:17601769 .

21. King TE Jr, Bradford WZ, Castro-Bernardini S, Fagan EA, Glaspole I, Glassberg MK, et al. A phase 3 trial of pirfenidone in patients with idiopathic pulmonary fibrosis. N Engl J Med. 2014;370:2083-2092.

22. Richeldi L, du Bois RM, Raghu G, Azuma A, Brown $\mathrm{KK}$, Costabel $U$, et al. Efficacy and safety of nintedanib in idiopathic pulmonary fibrosis. N Engl J Med. 2014;370:2071-2082.

23. Seeger W, Adir Y, Barberà JA, Champion H, CoghIan JG, Cottin V, et al. Pulmonary hypertension in chronic lung diseases. J Am Coll Cardiol. 2013;62 (Suppl):109-116.

24. Cottin V. Clinical case: combined pulmonary fibrosis and emphysema with pulmonary hypertension-clinical management. BMC Res Notes. 2013;6(Suppl): S2.

25. Raghu G, Behr J, Brown KK, Egan JJ, Kawut SM, Flaherty KR, et al. Treatment of idiopathic pulmonary fibrosis with ambrisentan: a parallel, randomized trial. Ann Intern Med. 2013;158:641-649. 
26. Kishaba T, Shimaoka Y, Fukuyama H, Yoshida K, Tanaka M, Yamashiro S, et al. A cohort study of mortality predictors and characteristics of patients with combined pulmonary fibrosis and emphysema. BMJ Open. 2012;15:2(3).

27. Papiris S, Manali E, Kolilekas L, Kagouridis K, Triantafillidou C, Tsangaris I, et al. Clinical review: Idiopathic Pulmonary Fibrosis Acute Exacerbations: Unravelling Ariadne's thread. Crit Care. 2010;14:246.

28. Sato T, Teramukai S, Kondo H, Watanabe A, Ebina M, Kishi K, et al; Japanese Association for Chest Surgery. Impact and predictors of acute exacerbation of interstitial lung diseases after pulmonary resection for lung cancer. J Thorac Cardiovasc Surg. 2014; 147: 1604-1611.

29. Lee T, Park JY, Lee HY, Cho YJ, Yoon HI, Lee JH, et al. Lung cancer in patients with idiopathic pulmonary fibrosis: Clinical characteristics and impact on survival. Respir Med. 2014;108:1549-1555.

30. Tomassetti S, Gurioli C, Ryu JH, Decker PA, Ravaglia
C, Tantalocco P, et al. The impact of lung cancer on survival of idiopathic pulmonary fibrosis. Chest. 2015;147:157-164.

31. Kwak N, Park CM, Lee J, Park YS, Lee SM, Yim JJ, et al. Lung cancer risk among patients with combined pulmonary fibrosis and emphysema. Respir Med. 2014;108:524-530.

32. Minegishi $\mathrm{Y}$, Kokuho $\mathrm{N}$, Miura $\mathrm{Y}$, Matsumoto $\mathrm{M}$, Miyanaga A, Noro R, et al. Clinical features, anti-cancer treatments and outcomes of lung cancer patients with combined pulmonary fibrosis and emphysema. Lung Cancer. 2014;85:258-263.

33. Moyer VA. U.S. Preventive Services Task Force. Screening for lung cancer: U.S. Preventive Services Task Force recommendation statement. Ann Intern Med. 2014;160:330-338.

34. King C, Nathan SD. Identification and treatment of comorbidities in idiopathic pulmonary fibrosis and other fibrotic lung diseases. Curr Opin Pulm Med. 2013;19:466-473. 